Hispania, 2019, vol. LXXIX, n. ${ }^{\circ}$ 262, mayo-agosto, págs. 389-414 ISSN: 0018-2141, e-ISSN: 1988-8368, https://doi.org/10.3989/hispania.2019.011

\title{
Socialización española de la monarquía saboyana: la visita a Galicia de Amadeo I*
}

\author{
Margarita Barral Martínez ${ }^{1}$ \\ Universidad de Santiago de Compostela \\ Margarita.barral@usc.es
}

RESUMEN: En la difusión de la identidad española durante la segunda mitad del siglo XIX las visitas reales fueron ejemplos de ceremonias civiles - acompañadas del repertorio religioso y castrense de la época-explotadas a modo de politicas públicas para la difusión de la nation-building, participando así en la conformación de las identidades políticas y culturales. Este artículo propone incorporar el estudio de la monarquía saboyana desde la combinación del poder político y simbólico a partir de un episodio concreto: la visita a Galicia de Amadeo I en agosto de 1872. A través del ceremonial monárquico desplegado de cara a la legitimidad de la nueva dinastía, pretendemos analizar el verdadero alcance de la nueva Corona en la socialización y nacionalización de la misma cuando, en principio, los actores sociales que la sustentaban no se reconocían ni en la forma ni en la persona que la representaba. Indagaremos en dos aspectos fundamentales: la proyección política de la visita y la percepción social de la misma. Nuestras fuentes serán las crónicas y reportajes hemerográficos, tanto la prensa provincial y regional como la

* Este artículo forma parte de los resultados de un proyecto de investigación financiado por el Plan Nacional de I+D, Subprograma Generación del Conocimiento [HAR2015-66532-P] titulado «Corte, Monarquía y Nación liberal (1833-1885). En torno al Rey y la modernización política de España en el siglo XIX».

Quisiera dejar constancia de mi agradecimiento a los evaluadores del texto original presentado, por sus correcciones y comentarios.

Siglas utilizadas: Archivo General de Palacio, Sección Reinados, Fondo Amadeo I, Madrid (AGP, RR, AMI); Ministero degli Affari Esteri. I Documenti Diplomatici Italiani, Roma, (MAAEE, DDI); Arquivo Histórico Municipal, A Coruña (AMC); Biblioteca Municipal de Estudos Locais, A Coruña (BMEL); Arquivo Municipal, Ferrol, A Coruña (AMF).

${ }^{1}$ ORCID iD: https://orcid.org/0000-0001-6621-8561.

Copyright: (C) 2019 CSIC. Este es un artículo de acceso abierto distribuido bajo los términos de una licencia de uso y distribución Creative Commons Reconocimiento 4.0 Internacional (CC-BY 4.0) 
de edición central, junto con documentación del Archivo General de Palacio (Madrid), del Ministero degli Affari Esteri (Roma), del Arquivo Histórico Municipal (A Coruña), de la Biblioteca Municipal de Estudos Locais (A Coruña) y del Arquivo Municipal (Ferrol-A Coruña).

PALABRAS CLAVE: monarquía; nacionalización; visitas reales; España; Amadeo I; Galicia.

\section{Spanish socialisation of the Savoyard Monarchy: Amadeo I's visit to Galicia}

ABSTRACT: In the bid to disseminate Spanish identity in the second half of the nineteenth century, royal visits were examples of civil ceremonies - accompanied by the religious and military repertoire of the day - which were used in public policies to further nation-building efforts, thus helping to shape political and cultural identities. Based on the specific episode of Amadeo I's visit to Galicia in August 1872, this article suggests that the study of the Savoyard monarchy should be included in this approach in view of its combination of political power and symbolic power. Through an analysis of the monarchical ceremonies deployed with a view to legitimizing the new dynasty, we explore the new Crown's actual reach in relation to the dynasty's socialization and nationalization at a time when, in principle, the social actors underpinning it did not themselves identify with either the form itself or the person representing it. We will investigate two critical aspects: the political implications of the visit and social perceptions of it. Our sources will be newspaper chronicles and stories, including both the provincial and regional press and central editions, together with documents from the General Palace Archive in Madrid, the Ministry of Foreign Affairs in Rome, the Municipal Historical Archive in A Coruña, the Local Studies Municipal Library in A Coruña and the Municipal Archive in Ferrol, A Coruña.

KEY WORDS: monarchy; nationalisation; royal visits; Spain; Amadeo I; Galicia.

CÓMO CITAR ESTE ARTÍCULO/CITATION: Barral Martínez, Margarita, «Socialización española de la monarquía saboyana: la visita a Galicia de Amadeo I», Hispania, 79/262 (Madrid, 2019): 389-414. https://doi.org/10.3989/hispania.2019.011.

Mi pare abbiamo fatto un viaggio al paese della luna².

\section{INTRODUCCIÓN}

«Voy a cumplir una misión imposible, España está dividida por muchos partidos que se unirán contra el Rey extranjero y yo deberé devolverle la Corona

\footnotetext{
${ }^{2}$ ROMANONES, 1965: 94.
} 
que me han ofrecido. Mi lealtad no podrá salvarme del furor de los partidos». Así refería la situación el mismo Amadeo I a un oficial que había estado con él en la batalla de Custoza en 1866 durante la guerra austro-prusiana; se lo comentaba momentos antes de su partida hacia Madrid para asumir la Corona ${ }^{3}$.

Desde la Ilustración, las imágenes y los símbolos identitarios fueron necesarios en Europa para construir un pasado nacional en espacios y comunidades políticas básicamente monárquicas, donde el rey aparecía como la encarnación de la nación; pasaba así a formar parte consustancial de la identidad nacional en construcción (nation-building) 4 .

Sin duda, uno de los desafíos más notables de los sistemas políticos contemporáneos fue resolver el encaje entre principio monárquico y principio liberaldemocrático, es decir: cómo hacer compatible la existencia de una figura no elegida en un sistema político basado en la igualdad jurídica y gobiernos populares y representativos. Por lo mismo, a lo largo del siglo XIX y comienzos del $\mathrm{XX}$ las monarquías se resignificaron y transformaron, se reinventaron, según la expresión de David Cannadine, convirtiéndose en "sistemas de engarce formal entre el nuevo orden liberal y las formas de poder procedentes del Antiguo Régimen», el poder simbólico-identitario de las nacionalidades, en definitiva ${ }^{5}$. Así, las Coronas y sus representantes pasaron por un proceso de nacionalización desde el siglo XIX utilizando como medios las iconografías, las ceremonias oficiales y los viajes y visitas reales, actos que convertían al monarquismo banal, expresión que desarrolla Olechnowicz para el caso británico a partir del nacionalismo banal de Billig ${ }^{6}$, a modo de políticas públicas del folclorismo de Estado $^{7}$ para articular una comunidad imaginada ${ }^{8}$ que asegurase la pervivencia de la institución, además de consolidar el carisma nacional y constitucional de los soberanos 9 . Para Walter Bagehot existía en todo este proceso algo de emotivo que respondería al encanto o majestuosidad, merced al misterio, que significaba la Corona ${ }^{10}$. Pero se requería para ello transitar desde los rituales del Antiguo Régimen hacia la popularización de la institución en la etapa constitucional, para su transformación en símbolo nacional por excelencia. Para ello, fue necesario «mancharse las manos», como dice Reyero ${ }^{11}$, tomando contacto directo con las masas para hacerse visible ante ellas y para ellas, explotar la

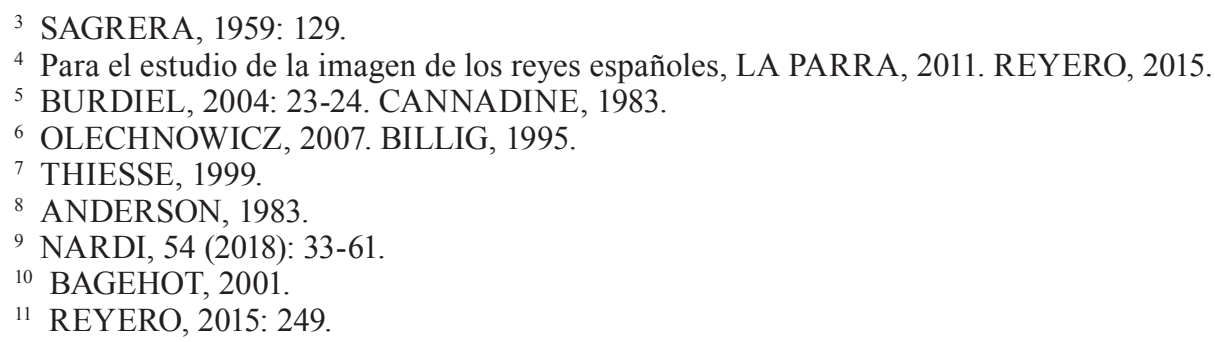


«monarquía escénica» de la que habla Javier Moreno ${ }^{12}$ para poseer poder, aunque éste fuese simbólico, como autoridad que era y pretendía continuar siendo ${ }^{13}$.

En las dos últimas décadas la bibliografía referida al papel de las monarquías en la construcción de las identidades nacionales ha sido prolífera, redundando en la idea de que la sociedad aceptaba e incluso demandaba las escenificaciones monárquicas ${ }^{14}$. Así, los viajes y visitas reales fueron explotados por las testas coronadas europeas para volverse populares y nacionales, acercando la institución y sus representantes al pueblo, el auténtico depositario de la soberanía, para convertirse en símbolo de consenso social y de continuidad histórica, además de tener el componente de delimitación territorial ${ }^{15}$. Sin duda, las aglomeraciones populares durante las visitas reales serían la mayor prueba de respaldo social y moral que avalaba a la monarquía moderna, una prueba con la que Amadeo I no contaría, como veremos.

En el estudio referido a la conversión de la Corona como emblema de la identidad nacional, el caso de Italia es uno de los más consumados. La dinastía Saboya fue un elemento clave en la configuración de la identidad nacional; el propio Víctor Manuel II y su sucesor Humberto I se presentaron como elementos indispensables de la identidad hegemónica, padres de la patria ${ }^{16}:$ «La figura del re e della casa regnante, infatti, ammantate da una luce sacra (...). I simboli e gli emblemi della monarchia furono strumentalizzati allo scopo di conferire un'aura quasi totemica alla rappresentazione del discorso nazionale e del nuovo sistema unitario $»^{17}$.

Para el caso de España los estudios sobre el proceso de nacionalización han sido fructíferos en las últimas décadas y las nuevas aportaciones demuestran cómo en el liberalismo español también se llevó a cabo un programa destinado a nacionalizar a las masas desde la imagen de la Corona y los monarcas ${ }^{18}$. Así, al igual que sus primos europeos, los monarcas constitucionales españoles transitaron hacia una transformación de la institución para adaptarla a la contemporaneidad. En España también se desarrollaron programas de visitas y viajes oficiales a las diferentes regiones del reino buscando los baños de multitudes y de popularidad a través de la representación performática de la monarquía ${ }^{19}$.

${ }^{12}$ MORENO LUZÓN, LXXIII/244 (2013).

13 GEERTZ, 1999.

14 VAN OSTA, 2006. GUAZZALOCA, 2009. BRICE y MORENO LUZÓN, 42 (2013). BANERJEE, BACKERRA y SARTI, 2017. SELLIN, 2017.

15 GEERTZ, 1993.

${ }^{16}$ LEVRA, 1997: 47-64. CAMMARANO, 2009: 67-91. BRICE, 2010.

17 MANCUSO, 2013: 154.

${ }_{18}$ Para el reinado de Amadeo I: MIRA ABAD, 2011; 37/2 (2007). GUTIÉRREZ LLORET y MIRA ABAD, 31 (2014).

${ }^{19}$ BARRAL MARTÍNEZ, 2019; 2016; 68 (2015); 2012. RUBÍ, 2013; 2012. MORENO LUZÓN, LXXIII/244 (2013). 


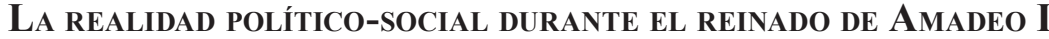

Tras el pronunciamiento del general Prim en 1868, que puso fin al reinado de Isabel II, las Juntas revolucionarias que se crearon a lo largo y ancho de la geografía española pretendieron asegurar el poder de la revolución. Con la creación de la Junta Superior revolucionaria, elegida en Madrid el 5 de octubre, el Gobierno provisional presidido por Serrano fue elegido tres días después y, con las elecciones a Cortes constituyentes del 15 de enero de 1869, las primeras con sufragio universal masculino para mayores de 25 años, se procedió a la elaboración y aprobación de una constitución que legitimara el nuevo régimen, de carácter democrático y monárquico, esto último entendido por muchos protagonistas de la septembrina como una traición.

El hecho de que el anticlericalismo del gobierno fuese manifiesto desde el inicio llevó a una reacción eclesiástica agresiva, sobre todo con aquellas disposiciones que abrían la puerta a la laicización de actos de la vida que habían sido de ejecución exclusiva de la Iglesia: el registro de los nacimientos, nupcias y defunciones. Así, muchos párrocos también se unieron a las partidas que apoyaron la nueva sublevación carlista tras los resultados de las elecciones de abril de 1872, donde el pretendiente había perdido trece escaños en unos comicios definidos por las acusaciones de fraude ${ }^{20}$.

Amadeo de Saboya, segundo hijo del rey de Italia Víctor Manuel II, símbolo de monarca demócrata, fue elegido por las Cortes el 16 de noviembre de 1870, aspecto discordante, cuando menos, con la legitimidad monárquica. Como muy bien apuntó Emilio Castelar, los reyes no podían salir de una asamblea ni de una urna electoral ${ }^{21}$. La misma prensa satírico-republicana como la revista Gil Blas se refería al «raro caso de monarca electivo que debía ganarse el favor popular $\rangle^{22}$. Debemos recordar también que otro elemento característico de estos años fue la publicidad que consiguieron las diferentes alternativas políticas, con multitud de nuevas publicaciones periódicas y de revistas, humorísticas unas y de calado político-intelectual otras, al abrigo de la libertad de expresión decretada en la Constitución de 1869 (Título 1º art. 17). Esta nueva realidad propició la aparición de publicaciones ilustradas como La Ilustración Española y Americana (1869) y La Ilustración de Madrid (1870), ambas «alfonsinas», la reaparición de El Combate (1870), anticlerical, antimonárquico y militante de la revolución, o el semanario satírico-republicano La Campana de Gràcia (1870).

${ }^{20}$ HIGUERAS CASTAÑEDA, 2018. TOLEDANO GONZÁLEZ, 14 (2015). BARREIRO FERNÁNDEZ, 2008.

${ }^{21}$ ROMANONES, 1935: 375.

22 Gil Blas, Madrid, 05-01-1871. 
El duque de Aosta contó con 191 votos a favor del total de 311 diputados que el día 16 de noviembre de 1870 asistieron a la sesión de Cortes ${ }^{23}$. Fue el primer intento de una verdadera monarquía democrática en España, con un rey no depositario de la soberanía, según establecía la Constitución, y con unas funciones ejercidas por los ministros; un rey «que reina y no gobierna» ${ }^{24}$.

Inglaterra seguía siendo el modelo de democracia para los Estados europeos, junto con la conversión de la imagen de la monarquía en el emblema por excelencia de la autoestima nacional ${ }^{25}$. Sin duda, ambos propósitos animarían al rey Amadeo I en su proyecto de socializar la monarquía Saboya en España, pero era un joven de 25 años que «desconocía de España la historia, la lengua, las instituciones, las costumbres, los partidos, los hombres» ${ }^{26}$. Tampoco vislumbraba talento ni carácter para el gobierno, al parecer. Aunque pretendió ser la imagen de un soberano burgués y demócrata, había recibido una educación acorde a su estatus. Era, en definitiva, «una criatura del Risorgimento italiano, en cuyo universo espiritual, nacional-romántico y liberal, creció» ${ }^{27}$.

Para compensar algunos de sus déficits en cuanto a imagen, defendemos la tesis de que Amadeo I se apoyó en su esposa, $\mathrm{M}^{\mathrm{a}}$ Victoria dal Pozzo, ejemplo moral de madre de familia y religiosa, presentada como encarnación del modelo burgués de feminización del poder a través del bello ángel del hogar, esposa generosa que vivía en constante desvelo ${ }^{28}$ - en contraste directo con la familia de Isabel II-. Así, a ella correspondían las obras de beneficencia, la atención de los necesitados y asistir «piadosamente a largas historias de miseria y dolores $\rangle^{29}$. La caridad era uno de los referentes morales del momento y la realeza europea pretendió rentabilizarla, en tándem con la religiosidad, como elemento de configuración de su imagen pública al estar dirigidas fundamentalmente hacia el pueblo.

María Victoria era, además, una mujer inteligente y culta que hablaba varios idiomas, entre ellos el castellano, lo que también contrastaba con la imagen previa de Isabel $\mathrm{II}^{30}$, y tenía sentido de Estado e interés por los asuntos públi$\cos ^{31}$. Pero el reinado de Amadeo I fue, en realidad, un fracaso tras un período

23 Además, hubo 27 votos a favor de Montpensier y 1 a la duquesa, 8 a Espartero, 63 a la república federal, 2 al príncipe Alfonso y 19 votos en blanco. FONTANA, 2007, vol. VI: 366. BAHAMONDE, 1994: 569.

${ }^{24}$ PÉREZ GALDÓS, 2007: 579.

25 WILLIAMS, 1997.

26 PI y MARGALL, 1970 [1873]: 54

27 KLEINMANN, 1999: 259.

${ }^{28}$ REYERO, 2015: 160.

29 AMICIS, 1906: 137. AGP, RR, AMI, caja 32, exp. 2; caja 34 exp. 8; caja 43, exp. 8.

${ }^{30}$ Para un análisis comparado entre Isabel II y $\mathrm{M}^{\mathrm{a}}$ Victoria de Saboya, GUTIÉRREZ LLORET y MIRA ABAD, 31 (2014): 139-166.

${ }^{31}$ MIRA ABAD, 2011: 308. 
de poco más de dos años. Para María Sierra, «el aprendizaje de la democracia debió de resultar, desde luego, conflictivo (...), como bien expresa, por ejemplo, el recurso de carlistas y republicanos a la alianza electoral [1871] $\rangle^{32}$. Además, aunque su origen extranjero e incluso su juventud pretendieron ser utilizados como valores añadidos para convertirlo en referencia simbólica de una identidad nacional moderna, el efecto fue el contrario. Este rasgo incluso se percibió en contraposición al ideal burgués de iniciativa y superación de la juventud, dejándose ver un rey demasiado joven e inexperto.

Este contexto también ayuda a entender la indiferencia e incluso desprecio hacia el rey burgués, sencillo y despojado de toda suntuosidad, por parte de los nobles. Muchos de ellos vieron en la figura de Amadeo I un medio más de la revolución que los llevaría a la pérdida de sus privilegios; de ahí su apoyo a la dinastía Borbón. Desde el inicio del reinado, parte del gobierno, sobre todo los «alfonsinos» agrupados en torno a la figura de Cánovas, las viejas aristocracia y nobleza, e incluso, la misma opinión pública también mostró su escepticismo - cuando no frialdad y rechazo directo - por el nuevo soberano, cuyo gran valedor, el general Prim, había fallecido víctima de un atentado dos días antes de la llegada de Amadeo a Cartagena, puerto por el que entró en España el 30 de diciembre de 1870. Paradójicamente, el resto de casas reales y gobiernos europeos, a excepción de la Santa Sede, aceptaron la proclamación del duque de Aosta como monarca de España, cuestión que agradaba al propio Víctor Manuel II al considerar que daba «sicurezza di una larga maggioranza alle Cortes $»^{33} \mathrm{y}$, por tanto, «l'avenir [serait] aussi facile à combiner» ${ }^{34}$. En realidad, la injerencia del soberano italiano en los asuntos del reinado de su hijo fue una percepción errónea del rey constitucional-democrático, confundiendo la política exterior italiana con las ambiciones de su propia dinastía ${ }^{35}$.

\section{Socialización ESPAÑOLA DE LA MONARQUía SABOYANA}

El mismo Víctor Manuel había enviado a sus dos hijos mayores, Humberto y Amadeo, a recorrer y hacerse visibles en los territorios del reino de Italia con el fin de afianzar su posición dinástica. Pero, además, los Saboya hicieron extensible al extranjero la instrumentalización de los viajes y los jóvenes príncipes conocieron las monarquías vecinas en los períodos vacacionales. Cuando

32 SIERRA, 2017: 339.

33 Visconti Venosta a Cerruti, Florencia, 27-10-1870, MAAEE, DDI, Seconda Serie, 18701896, vol. I., doc. 381: 323.

34 Vittorio Emanuelle II a Visconti Venosta, Turín, 02-11-1870, MAAEE, DDI, Seconda Serie, 1870-1896, vol. I., doc. 442: 368.

${ }^{35}$ PASCUAL SASTRE, 1995: 473. 
Amadeo I llegó a España ya había estado en Francia, Inglaterra, Bélgica, Suecia, Dinamarca, Portugal, Turquía, Egipto y también España, a la que había venido de visita de cortesía (y como turista) a Isabel II en el verano de 1865, una vez que ésta, por consejo del presidente O'Donnell, reconociera a la monarquía italiana ${ }^{36}$. Esta estancia fue muy comentada en la prensa al especularse que la razón última del viaje del príncipe había sido su compromiso matrimonial con la infanta Isabel, la Chata; pero sobre el hipotético enlace no se llegó a concretar nada ${ }^{37}$. Tras desembarcar en Cádiz el 23 de agosto, procedente de Lisboa a donde había ido para visitar a su hermana pequeña $\mathrm{M}^{\mathrm{a}}$ Pía, esposa del rey Luis $\mathrm{I}^{38}$, el príncipe italiano fue recibido por el marqués de Alcañices, gobernador civil de Madrid ${ }^{39}$. Visitó Sevilla, Málaga, Córdoba y Granada para dirigirse a continuación a Madrid, a donde llegó el día 3 de septiembre. Asistió a una corrida de toros, la fiesta del pueblo por excelencia, y presenció un simulacro de tiro en Carabanchel comandado por el general Serrano ${ }^{40}$. Finalmente, el día 6 viajó a San Sebastián en el tren del norte, donde fue recibido al día siguiente por la reina Isabel II y su marido, Francisco de Asís, la Infanta Isabel y el resto de la corte que acompañaba a la Familia Real en su estancia de verano en el palacio de Narros $^{41}$. Después de asistir a la cena con los anfitriones, Amadeo paseó por las calles del pueblo de Zarautz admirando las casetas y bailando el aurresku en la romería del Prado Grande. El día 9 se dirigió a San Sebastián para continuar desde allí su viaje a Francia ${ }^{42}$. Al parecer, el duque «conservó de aquel viaje un recuerdo imperecedero (...). La impresión que guardó (...) fue de algo lejano e impalpable, de un sueño oriental irrealizable» ${ }^{43}$.

El duque de Aosta era de complexión menuda, pero la práctica del deporte le había conferido agilidad. Tenía tres pasiones: la natación (su afición a los baños en el mar le endilgó el apelativo de «rey pez»), la equitación, y las marchas militares, esto último muy extendido entre las sagas monárquicas de la época a la hora de representar el poder regio. Pero siempre se consideró a sí mismo un rey de prestado en una corte borbónica; su condición de extranjero fue un obstáculo permanente para el hipotético arraigo de la monarquía ${ }^{44}$. Por

${ }^{36}$ La Época, Madrid, 11-09-1865.

${ }^{37}$ La Regeneración, Madrid, 23, 24 y 29-08-1865. La España, Madrid, 25-08-1865. La Esperanza, Madrid, 12-09-1865. La Época, 09 y 13-09-1865. El Contemporáneo, Madrid, 12-09-1865. SAGRERA, 1959: 61-68.

38 La Nación, Madrid, 27-08-1865.

39 José Osorio y Silva, duque de Sesto y marqués de Alcañices, sería después (siempre fiel a la dinastía de Borbón) uno de los personajes más influyentes de la Restauración de Alfonso XII.

${ }^{40}$ La Iberia, Madrid, 24-08-1865. La Época, 06-09-1865. El Contemporáneo, 06-09-1865.

${ }^{41}$ La Época, 08-09-1865. El Contemporáneo, 10.09.1865.

${ }^{42}$ La Esperanza, 07-09-1865. El Contemporáneo, 06-09-1865. SAGRERA, 1959: 67.

43 SAGRERA, 1959: 62-63.

${ }^{44}$ MIRA ABAD, 2011: 295. 
ello fue consciente de que necesitaría pasearse por la geografía del reino para socializar su imagen y nacionalizar la nueva dinastía. Así, junto con los políticos del gobierno, especialmente Ruiz Zorrilla, y las élites locales afines a la nueva dinastía, las menos, se desarrolló un programa de proyección social de la dinastía, con el fin de acceder al poder, ejercerlo y conservarlo, o lo que es lo mismo, definir la majestad del nuevo reinado ${ }^{45}$ para «canalizar la voluntad popular sin romper con la legalidad histórica de la monarquía» ${ }^{46}$ y continuar con ello la nacionalización española en clave monárquica (saboyana).

Para justificar la dinastía extranjera, de escasa tradición pero símbolo del liberalismo, los historiadores del régimen, como Antonio Pirala, vincularon la implantación de la nueva familia con la regeneración del país y defendieron las raíces que vinculaban a los Saboya con los Austrias, a través de la figura de Carlos I, y con los Borbones, a través de la de Felipe $\mathrm{V}^{47}$. Las referencias historicistas, igual que se hiciera previamente con Isabel II y después se hará con Alfonso XII, buscaban en todo momento vincular el pasado con el presente. Desde Italia también se recordaba el origen latino de ambos pueblos, un pasado común que enfatizaría la «civilización latina». Cuando tal pretensión no fue posible, tras la abdicación, se dio la imagen de una España analfabeta y dominada por grandes pasiones, es decir, fanatizada ${ }^{48}$.

La actividad pública desarrollada por los monarcas para visibilizar y dinamizar su imagen, con el fin de recrear el nation-building necesario para su aceptación y permanencia, se llevó a cabo a partir, sobre todo, de tres medidas:

1. La continuidad de la antigua tradición de ennoblecer a las personas más cercanas a su figura y a los políticos más destacados, a pesar de ser este un aspecto que se contradecía con su condición liberal-demócrata. Pero fue una política de ennoblecimiento diferente a la desarrollada por Isabel II, porque se dirigió a las élites empresariales, burguesas y culturales. La concesión de nuevos títulos nobiliarios, además de robustecer la elite del poder, también buscó compensar el contexto hostil de la antigua nobleza partidaria de los Borbones y comandada, sobre todo, por el marqués de Miraflores y el duque de Alba ${ }^{49}$. De esta época proceden los títulos de Urquijo y Casariego como ejemplos significativos, además del de Príncipe de Vergara, con el que se pretendió sacar rédito

\footnotetext{
${ }^{45}$ MIRA ABAD, 37/2 (2007): 1-24; 2011: 302.

46 BOLAÑOS MEJÍAS, 1999: 24.

47 PIRALA, 1870: 203.

48 Citado en MIRA ABAD, 2011: 315-316.

49 Cerruti (embajador italiano en Madrid) a Visconti Venosta (ministro de Exteriores italiano), Madrid, 09-11-1870, MAAEE, DDI, Seconda Serie, 1870-1896, vol. I. doc. 493: 419.
} 
al prestigio y popularidad de Espartero ${ }^{50}$; entre el reconocimiento a pensadores liberales destacó el del gallego Manuel Colmeiro como miembro de la Real Academia de Ciencias Morales y Políticas.

En esta práctica de ennoblecimiento también se encuadra el intento por parte del matrimonio Saboya de elevar el nivel de concurrencia de la nobleza y alta sociedad al Palacio de Oriente a través de la organización de cenas oficiales los viernes. Sin embargo, buena parte de los invitados declinaban asistir justificándose con las excusas más variadas $^{51}$.

2. La socialización de su imagen a través del órgano de propaganda por excelencia del Estado, la Gaceta de Madrid, conocedores como eran el mismo Amadeo I y los miembros del gobierno de la importancia adquirida por los medios de comunicación, periódicos, semanarios y revistas. Desde esta cabecera y a través de numerosa información referida a las actividades del rey y su familia se buscó modelar la imagen de la monarquía democrática que detentaba, al mismo tiempo que se pretendía fagocitar la ridiculización que se hacía del soberano con motes y caricaturas $^{52}$. Pero fue una labor titánica ante el desafío de la libertad de expresión, lo que restaría influencia a esta publicación ${ }^{53}$.

3. Siguiendo su propia experiencia personal, la tercera de las medidas fue la programación de una serie de visitas reales a diferentes provincias y ciudades, con el fin de afianzarse (socializarse) por todo el reino, no sólo en la capital. En estos desplazamientos el rey se descubrió, se acercó físicamente al pueblo, reconociendo así, aunque fuese de forma simbólica, la supremacía de la nación ${ }^{54}$.

El primer viaje de los monarcas fue a Alicante en marzo de 1871, donde los efectos de la fiebre amarilla de finales de 1870 habían supuesto alrededor de 1.600 víctimas $^{55}$. A partir de esta primera experiencia se organizan dos giras de visitas reales, sin causa sobrevenida o por catástrofe natural alguna, durante los meses de verano, aprovechando el período de descanso vacacional. El presidente, Ruiz Zorrilla, remitió una circular a los gobernadores provinciales el 30 de agosto de 1871 recomendando ajustar sus conductas a las circunstancias del momento en las celebraciones públicas durante las visitas reales. Así, se recomendaba evitar lo que aconteciera en «otros tiempos», donde «costosos

\footnotetext{
${ }^{50}$ SHUBERT, 2018: 512-513.

51 MIRA ABAD, 2011: 297.

52 Gil Blas, 11-08-1872. La Campana de Gràcia, Barcelona, 15-08-1872.

53 Véase el texto de SAPAG MUÑOZ de la PEÑA, 11 (2006): 199-215.

${ }^{54}$ MIRA ABAD, 2011: 303.

${ }^{55}$ ROCA, 1871: 6.
} 
festejos, ordenados no pocas veces bajo la presión de las Autoridades superiores, o ideadas por cierto espíritu de vanidad en algunas corporaciones», habían desencadenado gastos excesivos. Ante la penuria económica imperante en el país sería «altamente censurable» proceder de igual modo. Esta misiva se reprodujo después en la Real Orden publicada el 16 de julio de 1872, en el segundo gobierno Ruiz Zorrilla, donde se recomendaba prescindir de costosas manifestaciones oficiales y que se dejara a los habitantes expresar «espontánea y sencillamente los sentimientos que abriguen para su Real Persona $\rangle^{56}$.

Los viajes programados por el gobierno y el rey fueron realizados por Amadeo sin la compañía de su esposa. Uno de ellos fue al centro, noreste y levante español en septiembre de 1871, visitando Madrid, Valencia, Castellón, Tarragona, Barcelona, Girona, Lleida, Zaragoza, Navarra y Logroño, donde el recibimiento que le dispensó el general Espartero, el Pacificador, fue utilizado como medio de «consagración de[1] rey» ${ }^{57}$. El segundo viaje fue el realizado a las provincias del noroeste, entre julio y agosto de 1872 cuando visitó Santander, Gijón, Avilés, Ferrol y A Coruña.

Según las crónicas oficiales los enclaves visitados experimentaban «un movimiento extraordinario», aumentaban en población «con más de 20.000 forasteros» y sobresalía «la animación y bullicio propios de los días festivos (...) que forman la fisonomía especial (...) comparado con los días laborables (...). Todas las estaciones que se halla[ban] en el trayecto (...) estaban decoradas, en todas había arcos, ondeaban banderas y gallardetes, no faltaban músicas y el gentío era inmenso (...). Llovie[ron] sobre S.M. versos y flores, [era] vivo el entusiasmo, crecientes las manifestaciones de adhesión y de afecto» ${ }^{58}$. Presidían las estancias los Te Deum (acto de acción de gracias) celebrados al llegar a cada lugar junto con la solemnidad pausada de los disparos de artillería ${ }^{59}$. Los factores religioso y castrense, sobre todo, estuvieron muy presente en las visitas del monarca, aspectos con los que, igual que sus vecinos europeos, se pretendió configurar una imagen de rey católico, a pesar de ser hijo de rey excomulgado, y de rey soldado o soldado real, aquel que daría su vida por la patria... española.

Sin embargo, esta imagen ideal del recibimiento de los soberanos contrastó con la realidad de los hechos. La prensa satírica y anti-monárquica como $\mathrm{El}$ Combate comentó que Amadeo "soñaba» que se hacía "popular», sabiendo que cualquier parecido entre sueño y realidad es mera coincidencia ${ }^{60}$; y la ultra-

${ }_{56}$ Diario Oficial de la Provincia de La Coruña, La Coruña, 23-07-1872, AMC, exp. C-989 (11).

57 La Iberia, Madrid, 01 y 03-10-1871. SHUBERT, 2019: 509-510.

58 PIRALA, 1871: 276, 345, 376 y 389.

59 ROCA, 1871: 19.

${ }^{60}$ El Combate, Madrid, 29-12-1872. 
católica y anti-amadeísta como El Pensamiento Español habló de «la fabricación del entusiasmo popular» para «el monarca actor» ${ }^{61}$. En realidad, Amadeo I no solo sufrió el rechazo de la nobleza y de los aristócratas, del clero y de parte del ejército sino también la indiferencia de las clases populares. Y las clases medias, supuestas receptoras de la imagen burguesa del rey, no suponían todavía en el entramado social una realidad hegemónica. Así, desde el inicio de su mandato toda la programación en favor de su imagen y de la dinastía se topó con la propia fisionomía de un pueblo todavía muy tradicional a la hora de entender la monarquía democrática y, además, foránea, con la que no se identificaba en la configuración de la pretendida identidad nacional.

\section{La visita de Amadeo I a Galicia en 1872}

El siglo XIX en Galicia fue una etapa negativa en términos generales para la economía: la desarticulación del sector agrario tradicional, sin la contrapartida de una industrialización en auge, fueron factores que contribuyeron a esta situación. En el caso del sector primario, la base de la riqueza del Estado, se trataba de una agricultura limitada por la organización y explotación de la propiedad a partir del foro, con unas técnicas de cultivo todavía muy tradicionales y con un grupo rentista fuerte: fidalgos y clero. Sin embargo, entre las décadas de 1870 y 1880 se inició ya una nueva etapa donde se consolidó la pequeña explotación campesina que comenzaba a innovar, despegó la industria conservera del pescado a partir de la tradición salazonera y la región quedó definitivamente unida por vía férrea al territorio estatal a través del núcleo de Monforte (1883), favoreciendo su integración en el mercado interior. Pero si existió un elemento definitorio de Galicia en la transición del siglo XIX al XX, no fue otro que la emigración, fenómeno humano que se convertiría en el motor de los cambios sociales, económicos, políticos y culturales.

La monarquía de Saboya coincide, además, con los primeros años del Rexurdimento, aunque desde la publicación de Cantares Gallegos, en 1863, hasta 1875 la edición en gallego fue escasa. En ensayo se editaron los últimos volúmenes de la Historia de Galicia de Benito Vicetto - siete tomos entre 1865 y 1873 - que contribuiría de forma decisiva a la creación de una conciencia diferencial gallega. Pero el referente literario fue Rosalía de Castro, figura esencial de la cultura gallega que gozó de simpatías durante el Sexenio para verse sometida a un ostracismo cultural desde $1875^{62}$. En 1872 se publicó la segunda edición de Cantares Gallegos y ya está preparando su poemario Follas Novas (1880). Otros autores que comenzaron a relacionarse con la cultura gallega en

${ }_{61}$ El Pensamiento Español, Madrid, 07-01-1871.
${ }_{62}$ VILAVEDRA FERNÁNDEZ, 1999: 119.

Hispania, 2019, vol. LXXIX, nº 262, mayo-agosto, págs. 389-414, ISSN: 0018-2141, e-ISSN: 1988-8368

https://doi.org/10.3989/hispania.2019.011 
los primeros años de la monarquía de Amadeo fueron Valentín Lamas Carbajal, Manuel Curros Enríquez, Eduardo Pondal - con el mito celta como fundador de Galicia - y Manuel Murguía.

Amadeo emprendió el 20 de julio de 1872 un viaje por las ciudades del norte que se extendió hasta el 24 de agosto. En Galicia estuvo entre los días 17 y 21 de agosto; durante su estancia visitó la ciudad departamental de Ferrol, entre el 17 y el 20, y la de A Coruña, en la que tan sólo estuvo los días 20 y 21, desde donde embarcó de nuevo para regresar a Santander. El monarca estuvo acompañado por el ministro de Gracia y Justicia, el gallego Eugenio Montero Ríos.

Hasta fechas tardías no se confirmó la visita. Debemos recordar que la pareja real había sufrido un atentado el 18 de julio en la calle Arenal de Madrid, al que habían reaccionado con una serenidad y entereza que propició que al día siguiente el rey fuera acogido «con applausi ed ovazioni (...). L'oggetto della universale ammirazione ${ }^{63}$, reportándole de forma momentánea unos minutos de la popularidad que tanto necesitaba para que «las raíces del Trono saboyano se adentrar[a]n en tierra hispánica ${ }^{64}$.

Si nos guiamos por la descripción de las fuentes y crónicas oficiales de la visita, sabemos que el día 17 a las cuatro de la tarde llegó a Ferrol la fragata Vitoria - la que había iniciado en Galicia el alzamiento de la Gloriosacapitaneada por el visitante regio. Fue recibido con salvas de ordenanza por el Capitán General, José Sánchez Bregua, y otras autoridades militares y civiles. Tras la bienvenida de las diputaciones provinciales de A Coruña y Pontevedra, de la comisión de la Audiencia y las corporaciones populares, accedió a la iglesia parroquial de San Julián «rodeado de un inmenso gentío que le aclamaba». Se ofició un Te Deum celebrado por el clero diocesano y castrense. A la salida del oficio religioso el monarca fue «objeto de una indescriptible ovación (...) arrojando de muchas casas particulares a su carruaje multitud de flores y palomas $\rangle^{65}$.

El día siguiente, el 18, el rey inició de nuevo con un oficio religioso, en la iglesia castrense y «siendo acompañado por una inmensa multitud que le aclamaba». A continuación, recorrió en carretela descubierta la calle Real, «adornada con elegantes arcos de triunfo construidos por el ejército y el partido radical, y también acompañado por el pueblo, que manifesta[ba] (...) evidentes muestras de su adhesión a la dinastía». Visitó el Arsenal del Astillero y los barcos en construcción, el cuartel de Dolores y las escuelas de Marinería. A su regreso, pasó por las inmediaciones de la escuadra inglesa fondeada en el

${ }^{63}$ R. di Martino (embajador italiano en Madrid) a Visconti Venosta (ministro de Exteriores italiano), Madrid, 19-07-1870, MAAEE, DDI, Seconda Serie, 1870-1896, vol. IV. doc. 23: 19.

${ }^{64}$ SAGRERA, 1959: 257-259.

${ }^{65}$ La Correspondencia de España, Madrid, 18-08-1872. 
puerto donde «las tripulaciones lo vitorearon repetidas veces» ${ }^{66}$. Inglaterra, que veía con simpatía el reinado de Amadeo de Saboya y siempre había apoyado a los progresistas, envió en esta ocasión una escuadra para cumplimentar y acompañar al rey ${ }^{67}$, quizá también para auxiliarlo en caso de necesidad, como veremos. A continuación, Amadeo I regresó a la Capitanía General, donde se alojó, «seguido de la misma multitud que a todas partes le acompaña[ba]». Por la tarde asistió a regatas con «el pueblo entusiasmado» y a las que también acudieron los botes ingleses.

El día 19 continuaba en Ferrol y en horario de mañana visitó el dique de la fragata Amadeo (la fragata Sagunto, rebautizada), los talleres, almacenes y la Escuela de Ingenieros, «rodeado y aclamado por un inmenso gentío». Por la tarde inspeccionó los buques de la escuadra inglesa y por la noche asistió a un banquete en su honor en la nave del almirante inglés, «a medida que la animacion y júbilo del pueblo [iba] cada día en aumento (...) aclamándolo con atronadores vivas» ${ }^{68}$.

El día 20 visitó a primera hora los establecimientos benéficos y a las nueve partió hacia A Coruña a bordo de la fragata Vitoria, escoltada por la escuadra británica y siendo «aclamado por la multitud». Desembarcó en la ciudad de los cristales al mediodía, donde fue recibido con salvas de cañones y «botes empavesados y llenos de gente, cuyos víctores se mezclaban con el estampido de los cañonazos, el eco de las músicas y el ruido de millares de cohetes». Se dirigió con su séquito a la iglesia de San Jorge donde tambien se ofició un Te Deum por el clero castrense, "pudiendo apenas abrirse paso por entre la muchedumbre, que no cesaba de aclamarle en toda la extensa carrera, vistosamente adornada con arcos, banderas y gallardetes, engalanados los balcones y llenos de señoras arrojando flores y palomas». En el edificio de Capitanía «recibió a las autoridades, corporaciones e infinidad de particulares y presenció desde el balcón el desfile de las tropas». Por la tarde visitó la Fábrica de Tabacos y el establecimiento de beneficencia. A las siete despachó con la corte y por la noche se presentó en el teatro para ser despedido «con nutridísimos aplausos» ${ }^{69}$.

La población disfrutó con «las lanchas vistosamente engalanadas, el repique de campanas, las marchas militares españolas e inglesas», las bombas de palenque y «las elegantes y ricas iluminaciones de los establecimientos públicos y principalmente de las casas particulares» que, sin duda, cambiaron por

${ }^{66}$ La Iberia, 20-08-1872. El Imparcial, Madrid, 20-08-1870. Expediente sobre los acuerdos tomados por esta corporación en vista del oficio remitido por el Sr. Gobernador de esta provincia participando la casi segura venida de S.M. a esta capital, 1872, AMC, C-989 (11). Expediente Visita del Rey Don Amadeo $1^{\circ}$. Días 17 y 20 de agosto de 1872, AMF, exp. C-699/14.

${ }^{67}$ GONZÁLEZ LÓPEZ, 1980: 664.

${ }^{68}$ La Iberia, 21-08-1872.

${ }^{69}$ La Iberia, 22-08-1872.

Hispania, 2019, vol. LXXIX, nº 262, mayo-agosto, págs. 389-414, ISSN: 0018-2141, e-ISSN: 1988-8368 
unas horas la imagen de ambas ciudades. Finalmente, el día 21 el rey revisó las tropas y fue a la Audiencia Territorial para, a continuación, ya al mediodía, embarcar de nuevo en la fragata Vitoria e iniciar su regreso a Santander, «recibiendo en el tránsito una inmensa ovación de todo el pueblo» y «un sin número de embarcaciones escolta[ron] a la falúa real» ${ }^{70}$.

Con respecto a la presencia de elementos de folclore e identidad autóctona gallega incluidos en la puesta en escena monárquica, lo único que hemos encontrado en las fuentes consultadas es una referencia a las «gaitas del país» en los botes que fueron a recibir al rey en Ferrol $^{71}$.

Una vez expuestos los hechos conviene un análisis de los mismos distinguiendo entre la prensa oficial y la no adicta. Con respecto a la primera, acabamos de comprobar que en todo momento se hizo eco del entusiasmo popular ante la ambientación y teatralidad monárquica, que aunque solo fuese por mera curiosidad, en alguna medida debió producirse realmente. La prensa recurrió a los telegramas de los propios ministros y autoridades militares que acompañaron al rey para dar los partes oficiales de la visita. El Imparcial, por ejemplo, como órgano más influyente del Sexenio y firme apoyo de Amadeo I, daba noticias del «entusiasmo siempre creciente que causa[ba] la presencia del rey» ${ }^{72}$ y reconstruyó crónicas con referencias al entusiasmo y regocijo popular semejantes a las publicadas durante la visita real previa, la de Isabel II, y las posteriores de Alfonso XII e incluso de Alfonso XIII ${ }^{73}$. Pero contrasta con esta posición cuando es la prensa no alineada la que publica los comentarios donde, además, en las crónicas referidas a las otras visitas, la prensa independiente y no afín o detractora se mantuvo al margen, como mínimo. No debemos olvidar que durante la visita de Amadeo, además de que las autoridades que recibieron al monarca y su corte no eran afines a la causa amadeísta, la libertad de expresión facilitaba mucho las cosas a la hora de editar comentarios y críticas.

$\mathrm{Si}$ bien es cierto que en los lugares visitados los representantes liberales en las instituciones, fundamentalmente diputaciones y gobierno civil, intentaron organizar los actos de recepción del rey, se encontraron absentismo, cuando no abierta hostilidad, en las demás fuezas políticas y actores sociales. El siguiente nivel recaía ya en las corporaciones municipales que, en muchos casos, no respondieron positivamente; ni en el caso de las ciudades directamente visitadas ni en las del resto de Galicia que podrían enviar representantes, como ocurrió en el caso de Vilagarcía de Arousa, donde el alcalde Cuevas del Valle tuvo serios problemas para organizar una comisión que se dirigiera a la ciudad de A Coruña a presentar sus respetos al soberano, ante las nulas «simpatías que

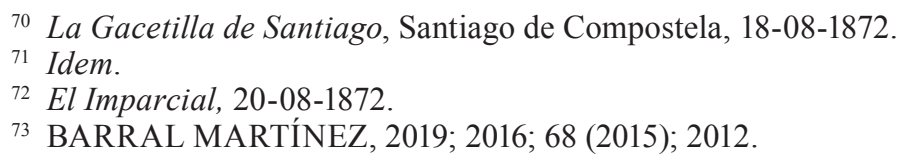


adornan a los individuos reunidos para con el Rey democrático (...) y la consiguiente repugnancia que en los mismos se desprende $\rangle^{74}$.

Para el caso de Ferrol, la Marina hizo preparativos para recibirle «pero en la población nada se notaba ni el entusiasmo sería gran cosa» ${ }^{75}$. El alcalde, José Calvet, que pretendió en todo momento dar una imagen de civismo y buenas formas, tuvo que soportar el desplante del clero parroquial y de parte del castrense, que se negaba a asistir al Te Deum celebrado en San Julián para recibir al rey «elegido» ${ }^{76}$. También fue necesario distribuir «una paga al Departamento y se daría otra la víspera de la llegada para producir calor ${ }^{77}$, además de recurrir a la Congregación de Nuestra Señora de los Dolores para disponer de afectos que pudieran adornar la Casa Consistorial durante la recepción del monarca además de solicitar ayuda a particulares para alojar a parte de la comitiva regia, una cuestión que no siempre fue acogida con buena disposición ${ }^{78}$.

Para el caso de la estancia en A Coruña también se recalcó en todo momento la ausencia del clero, «que se disponía (...) a ponerse enfermo», y cómo la condición republicana de la ciudad mostró hostilidad en todo momento. Varios particulares también se negaron a prestar sus muebles y el dueño de la Fonda Universal, al que se había propuesto preparar las comidas durante la permanencia de Amadeo, solicitó una retribucion exagerada y ser eximido «de responsabilidad en caso de envenenamiento ${ }^{79}$.

Además de que la visita fue recibida con frialdad y hostilidad, nos encontramos también con que las descripciones de los actos fueron igualmente hostiles en las ediciones no adictas. La prensa gallega referenciada, La Gacetilla de Santiago, de tendencia liberal-republicana en ese momento, y El Eco de Galicia, conservador-alfonsino, se manifestó declaradamente contraria, haciendo uso de la ironía y el desprecio al referirse a los actos y celebraciones realizados. Con respecto a la verdadera decoración que engalanó las ciudades, para el caso de Ferrol destacaron los desfiles y músicas militares, como no podía ser menos, además de la «iluminación general» durante la noche y algunos arcos, contrucciones efímeras que, junto a los construidos en A Coruña, fueron ejemplos de arte povera ${ }^{80}$. Para el caso de A Coruña, percalina y pinos constituyeron la decoracion fundamental - en lo que cabría suponer que eran mástiles engalanados - junto con un arco de follaje que se describe como de laurel y otras

${ }^{74}$ VIANA, 2014: 2.

75 El Eco de Galicia, Lugo, 08-08-1872.

${ }^{76}$ Carta del Teniente Cura de San Julián, Nicolás Silva y carta del Vicario general castrense de Ferrol, Vicente Alcayde, al alcalde de Ferrol, José Calvet, 14 y 16-08-1872, AMF, exp. C-699/14.

77 El Eco de Galicia, 08-08-1872.

78 AMF, exp. C-699/14.

${ }^{79}$ El Eco de Galicia, 13-08-1872.

${ }^{80}$ REYERO, 2015: 219.

Hispania, 2019, vol. LXXIX, n 262, mayo-agosto, págs. 389-414, ISSN: 0018-2141, e-ISSN: 1988-8368 
hierbas, reseñando que se debía al Partido Radical, siendo por tanto un acto de partido más que de la monarquía ${ }^{81}$.

En el mismo bando con el que el alcalde de A Coruña, Federico Tapia, republicano y firmante del Pacto federal galaico-asturiano en 1869, anunció la visita real, si bien es cierto que atribuyó al gobierno el hecho de recomendar reducir los gastos en los festejos, puso en evidencia su intención de limitar la recepción a estrictos términos de cortesía, además de aprovechar las instrucciones gubernamentales como pretexto para no realizar gastos ni recomendación alguna a la ciudadanía ${ }^{82}$. Con todo, el jefe republicano federal de Galicia, Ramón Pérez Costales, consideró que el alcalde se excedía en atenciones ${ }^{83}$.

El ambiente no parece mejorar con la publicación de un suelto que recogió El Eco de Galicia titulado «Lamentos del pueblo español». Un impreso donde se decía: «Es preciso hacerle oír [al rey] el lenguaje de la verdad, que por desgracia pocas veces llega a esas personas». A continuación, comparaba el estado de Madrid con el de la provincia, indicando que «mientras allí se anuncia en primero de mes el pago de las clases activa y pasiva, esta no ha cobrado un céntimo en A Coruña de los haberes de este año (...). Mientras cobran puntualmente 7,50 pesetas muchos individuos sin más méritos que el de haber sabido escalar el poder y desgobernar el país [referencia a la corrupción], los establecimientos de Beneficencia se hallan sin socorro, sin paga el clero y los maestros de escuela y sin cubrir otras mil atenciones, a la vez que se cobran (...) las contribuciones, para templar la sed de oro que devora a esos magnates $\rangle^{84}$.

Una imagen también muy distinta a la oficial de La Iberia, progresista, o incluso El Imparcial, fue la crónica que publicó de nuevo El Eco de Galicia el 22 de agosto acompañada de un suelto que se repartió «con profusión», firmado por el republicano Pérez Costales y dirigido a Amadeo. En el mismo, el autor decía acercarse al rey «con todo el respeto que me merece un hombre y toda la repugnancia que me inspira un rey. (...) Estáis, pues, rey Amadeo en país completamente enemigo, pero enemigo leal. Aquí no hay calles que se llamen del Turco ni del Arenal [alusión a los atentados sufridos por Prim y por los reyes respectivamente] (...). Pero, señor, si (...) queréis conocer el estado del país y las necesidades de los pueblos, cosa que me permitiréis ponga en duda, (...) escuchad, rey Amadeo (...) la miseria del pueblo: Vuestro ministro ha podido, rebuscando, remitir estos días algún dinero a Ferrol para acallar un tanto las quejas de aquel departamento, y no llega ni aun para cubrir la mitad de lo que allí se debe a los empleados». Y concluía: «Adiós, rey Amadeo. Los

${ }^{81}$ El Eco de Galicia, 20-08-1872.

${ }^{82}$ Bando anunciando la visita del Jefe de Estado, Amadeo de Saboya, a La Coruña, Federico Tapia y Segade, 19-08-1872, BMEL, doc. 11.

83 GONZÁLEZ LÓPEZ, 1980: 664.

${ }^{84}$ El Eco de Galicia, 13-08-1872. 
republicanos de La Coruña desean que continuéis vuestro viaje sin novedad y hacen fervientes votos por el advenimiento de su ideal político» ${ }^{85}$.

Como agravante, también circularon noticias referidas a la presencia de par-

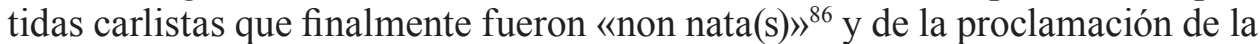
república en $\mathrm{Ferrol}^{87}$, algo que sucedería en realidad un mes y medio después de la visita del rey, entre el 10 y el 15 de octubre. Sin duda, esta última manifestación ayuda a ver con cierta nitidez el ambiente proclive al mismo alzamiento ya en los meses previos, lo que también nos lleva a pensar que quizá por esta razón el rey y el gobierno de Ruiz Zorrilla pretendieron desactivar dicho ambiente con una visita regia que se centró, casi exclusivamente, en la ciudad departamental.

Incluso se encuentran diatribas abiertamente insultantes, como aquella de El Combate (republicano federal) que tachaba al rey de «desgraciado» y donde se mezclaba el reproche de ser un advenedizo (il povero bambino) con el hecho de apoyarse en intereses extranjeros (ingleses) y de ser un monarca del Partido Radical, además de suponer un coste de 30 millones «por ir de allá para acá, y no hacer nada de provecho ${ }^{88}$. Este es el único dato que hemos localizado hasta la fecha de algún valor referido a los costes que pudo ocasionar la visita, pero sospechamos que se refiere a la asignación que desde el Estado se le hacía al rey tras la desamortización del Patrimonio Real efectuada con La Gloriosa. Frente a esto, en la mente del pueblo todavía estarían presentes las dádivas y la munificencia dispensadas por Isabel II a casas de beneficencia, pobres del pueblo, conventos y santuarios en su visita de $1858^{89}$.

El grado de desafección llegó a tal extremo que en El Eco de Galicia se hizo un llamamiento para «preparar la opinión por la legalidad existente, en favor de la causa del príncipe Alfonso [que] sostendrá las doctrinas monárquico constitucionales; combatirá el liberalismo racionalista y todo cuanto condene la Iglesia católica (...)». Estaba firmado por miembros de la redacción, entre los que se encuentra el mismo director, el conde de Pallares, y redactores como Nicandro García, José $\mathrm{M}^{\mathrm{a}}$ Castro, Antonio Camba, Alejandro Castro, Teolindo María Romero, Manuel Freire Calviño, Segundo Castro Pita, Vicente Ruso o José Pardo Dominguez ${ }^{90}$.

Así las cosas, este viaje vendría a ser un ejemplo de como los mismos mecanismos no obtendrán iguales resultados cuando los actores sociales que deberían sustentar la monarquía no se identificaban en la persona que la representaba.

\footnotetext{
${ }^{85}$ El Eco de Galicia, 22-08-1872.

${ }^{86}$ La Gacetilla de Santiago, 23-07-1872.

${ }^{87}$ La Gacetilla de Santiago, 27-07-1872.

${ }^{88}$ El Combate, 16-08-1872.

${ }^{89}$ BARRAL MARTÍNEZ, 68 (2015); 2012.

${ }^{90}$ El Eco de Galicia, 01-08-1872.
} 
La mayoría del pueblo gallego tampoco consideraba «que en la patria de los Alfonsos pu[diera] aclimatarse una dinastía extranjera, y mucho menos la dinastía de D. Amadeo. (...). No puede pensar como piensan los españoles (...). Extraño a nuestros usos, costumbres y tradiciones para sus ojos y su espíritu nuestra historia es un libro en blanco». Frente a él, el príncipe Alfonso era aclamado como representación de la «legitimidad tradicional y española (...); hijo de una madre común, la patria (...). El nombre de D. Amadeo nada dice, nada recuerda a los españoles, el de Alfonso solo compendia una magnífica epopeya», recordando a todos los Alfonsos que le habían dado como herencia su condición de «católico, casto, grande noble, generoso, sabio y justiciero» ${ }^{91}$.

Con respecto a la visita previa de Isabel II en 1858 y las posteriores de Alfonso XII en 1877, 1881, 1883 y 1884, si bien el protocolo de actuación de las celebraciones y ceremonias sigue unas pautas similares a las desarrolladas durante la visita de Amadeo I, las estancias de los Borbones fueron actos multitudinarios y emotivos para el pueblo, convirtiéndose en romerías gallegas españolizadas en clave monárquica (borbónica). Además, se explotó el valor moral de la munificencia de los reyes. Para el caso de la visita de Amadeo, aunque se justificó en la penuria económica la ausencia del ornato y percalina en las celebraciones, aspecto que también era acorde con el estilo de vida sencillo del soberano, la sociedad gallega mostró, sobre todo, indiferencia. El silencio del pueblo fue una evidencia muda pero elocuente, el mayor mensaje que recibió Amadeo I en Galicia.

Lo narrado hasta aquí nos muestra las tensiones políticas e incluso el estado real de la sociedad. Ante tanta desolación con respecto a la acogida popular del monarca, la corte inició su viaje de regreso a Santander el día 21, alegando que debía hallarse en la capital el 24. Frente a esto, se reprochaba que Amadeo debiera haber permanecido en A Coruña tres días y visitar también Vigo, Santiago y algún otro punto del territorio. Quizá tanta precipitación se debió al mismo hecho de considerar que su presencia en Galicia por más tiempo excedería en frialdad al recibimiento previo que había tenido en Asturias ${ }^{92}$, además de temer el inminente alzamiento republicano de Ferrol o, incluso, la posibilidad de un segundo atentado.

Aunque la finalidad de la estancia fuera obtener reconocimiento y prestigio, contando además con el precedente del viaje de Isabel II, lo cierto fue que los resultados fueron nulos en este sentido. En Galicia, los republicanos, alfonsinos, montpensieristas, carlistas, la nobleza y el clero tampoco se sumaron a la monarquía de Amadeo I. Los términos «entusiasmo» e «indescriptible» de la prensa oficial, junto con otros similares, no dejaron de ser objeto de burla en coplillas de la prensa satírica, que ridiculizaban en todo momento la

\footnotetext{
${ }^{91}$ El Eco de Galicia, 06-08-1872.

${ }^{92}$ La Esperanza, 26-08-1872.
} 
propaganda oficialista del evento ${ }^{93}$. Además, las ediciones no afines atribuyeron el objetivo propagandístico del viaje al Partido Radical y a «D. Manuel» (entiéndase Ruiz Zorrilla), más que al propio soberano ${ }^{94}$. Junto al hecho de utilizar la ironía para referirse a la propia figura de Amadeo I, que «se feste$\mathrm{ja}[\mathrm{ba}]$ a sí mismo» ${ }^{95}$, también se recurrió a la réplica argumentativa para desmontar la propaganda de la visita utilizando tres elementos irrebatibles:

1. La interpretación de la historia, un elemento también recurrente en las monarquías europeas del momento para legitimar las testas coronadas en la realidad contemporánea. De ello también dejó costancia Galdós, al escribir que la monarquía «traída de un italiano es como petardo puesto en el corazón del pueblo» ${ }^{96}$. La falta de majestad de la que habla Mira Abad no sólo la rechazaban sus detractores sino el mismo pueblo, que todavía prefería un «rey más real $»^{97}$. Aunque el monarca hubiese podido solventar su condición de foráneo y con poca majestad, era muy difícil poder vincular una monarquía de imagen democrática con una sociedad todavía muy sacralizada, donde la tradición y la historia (dinástica) seguían pesando demasiado, una historia donde la memoria del tiempo pasado se fundía con la imagen del presente.

Otro aspecto que progresistas y radicales, junto con el propio rey, infravaloraron, incluso ignoraron, fue la connotación identitaria autóctona. En realidad, el sentimiento de referencia al pueblo, a una patria, es anterior y más arraigado que el de pertenencia a una nación; y ambos conceptos no son equivalentes ni intercambiables ${ }^{98}$. Por lo mismo, al no incluirse en la performance monárquica desplegada durante la visita el origen geográfico (a través del tipismo y la referencia a la indumentaria regional) y la especificidad cultural más allá de las referidas «gaitas del país», no se avanzó en la socialización y nacionalización de la Corona saboyana.

2. La sociedad española en general y la gallega en particular todavía eran muy tradicionales. La revolución liberal había operado más en el plano político-jurídico que en el plano social, donde se seguía dialogando con aspectos del Antiguo Régimen. La Iglesia seguía teniendo mucho poder social y moral y aunque se explotó el recurso de la religiosidad al hacer

93 «Estos vivas son muy raros / no estoy hecho á cosas tales / ¿Son de fondos provinciales? / -Sí, señor, mas no son aros; / nos cuestan á cinco reales (sic)». El Garbanzo, Madrid, 15-08-1872.

${ }^{94}$ El Combate, 16-08-1872.

${ }^{95}$ La Esperanza, 26-08-872.

96 PÉREZ GALDÓS, 2007: 579.

${ }^{97}$ SPERONI, 1989: 81 y 90.

98 VIROLI, 2019. 
alarde de un monarca católico, devoto y practicante, aspecto con el que también se pretendió desactivar el hecho de ser hijo del rey excumulgado, en Galicia parte del clero también mostró su animadversión negándose a recibirlo. Además, en el afán progresista de los radicales no se explotó el fuerte valor moral de la beneficencia, una función que todavía se relacionaba con la caridad cristiana. Se evidencia como algo residual en el programa, reducida a una visita a la beneficencia de Ferrol momentos antes de partir hacia A Coruña ${ }^{99}$, donde también visitó por unos minutos las dependencias benéficas. Pero no se menciona depósito económico alguno. Sin embargo, y según consta en los originales que se conservan en el Archivo General de Palacio, en el viaje realizado a Alicante en marzo de 1871 los reyes Amadeo I y M $\mathrm{M}^{\mathrm{a}}$ Victoria sí depositaron donativos para conventos, viudas con hijos, alimentos para presos y establecimientos benéficos y sábanas para hospitales ${ }^{100}$. Cabe pensar entonces que la función caritativa fue algo estimulado sobre todo por la figura de la reina, empatizando con la imagen de feminización del poder.

3. Se refleja también el interés por parte de la oficialidad por la conexión entre la idea de progreso, de modernidad, y la monarquía. El progreso era uno de los estímulos del imaginario colectivo nacional. El ferrocarril, el telégrafo, la edición de revistas pintorescas e ilustradas y los álbumes con la fascinación de la fotografía como espejo de una nueva realidad social ante los cambios que implantaba la cultura liberal, a través de una compleja e inestable realidad política. Esta pretensión adquirió fuerza en la ciudad de Ferrol, en estrecha relación con la innovación tecnológica que se estaba desarrollando en el Arsenal y sus astilleros ${ }^{101}$; y a través de la visita a la Fábrica de Tabacos del barrio de A Palloza de La Coruña, una de las instalaciones fabriles más representativas de la Galicia del momento, con el aliciente de ser una concentración fundamentalmente femenina y de ideología federal. Emilia Pardo Bazán, que junto a otras damas de la aristocracia tampoco aceptaba al «rey extranjero», novelaría años después en La Tribuna que, desde entonces, las cigarreras de Marineda tenían «a quien echar la culpa de todos los males que afligían a la Fábrica» ${ }^{102}$.

Pero la prensa detractora, tanto la alfonsina como la republicana, también contrarrestó de forma directa y sin contemplaciones este discurso oficial de progreso con la veracidad de la misma realidad gallega. Enumeraron y exaltaron las necesidades económicas del momento y el olvido de la región desde el centralismo estatal.

${ }^{99}$ La Iberia, 21-08-1872.

${ }^{100}$ AGP, RR, AMI, caja 34, exp. 8.

101 Véase RAMIL, 1998.

102 BURDIEL, 2019: 81. PARDO BAZÁN, 2002: 207. 


\section{Conclusiones}

Una vez que llega a los individuos la transmisión de una identidad a través de mensajes directos o codificados, la asimilación del concepto de nación tendrá más o menos éxito en función de una serie de variables y donde el nivel privado y las circunstancias particulares justifican en buena medida la asunción de esa identidad. Para el caso de la monarquía se puede hablar de dos tipos de origen de la legitimidad: aquella de carácter político que le viene por la codificación constitucional, y otra simbólica, que no es menos importante a la hora de socializar y nacionalizar la institución. La vertiente simbólica procede de la historia (herencia y tradición dinástica) y se alimenta de su representación, la proyección pública y la percepción social para convertirse en vértice superior de la identidad nacional. Y es esa misma identidad nacional que asume o incluye la Corona la que determina el prestigio (dígase socialización) de la institución.

Para el caso de la dinastía Saboya en España entre 1871 y 1873, aunque sí se aunaron esfuerzos para llevar a cabo una socialización y nacionalización de la misma más allá de la legitimación política que le otorgaba la Constitución y su atípica elección en Cortes, no se consiguió asentar un discurso ni en torno a la legitimidad dinástica frente a los Borbones ni en torno a la legitimidad simbólica. Amadeo de Saboya pretendió enraizar una nueva dinastía moderna, burguesa, y para ello buscó construir su imagen sobre estos valores, al igual que otras monarquías vecinas y donde el recurso de los viajes reales también fue un elemento de promoción de la identidad nacional en construcción (nation building), caso de la visita a Galicia en 1872. Pero si bien es cierto que la realidad revolucionaria de la que emanó no lo favorecería, tampoco lo hizo la realidad social que imperaba. La monarquía tenía que ser cierto reflejo de la sociedad de su tiempo para ser asumida por el pueblo como elemento identitario, como símbolo nacional. Progresistas, radicales y el mismo rey se olvidaron de que la historia y la tradición eran componentes esenciales de la institución en una sociedad todavía muy definida por caracteres más propios del Antiguo Régimen que de las emergentes sociedades capitalistas del último cuarto del siglo XIX.

Además, pese a las nuevas formas que acompañaron al rey —en alguna media debidas a su educación en Italia-, que siempre mantuvo una correcta actitud política, juró la constitución, fue afable y sencillo en el trato y rechazó las camarillas que habían definido la corte isabelina ${ }^{103}$, en su imagen siempre pesó como una losa la condición de extranjero. Ante tanta adversidad social y política, que lo llevaron a pensar que había hecho «un viaggio al paese della luna», tal y como le confesó a su amigo íntimo el marqués de Dragonetti ${ }^{104}$, Amadeo de Saboya utilizó como motivo ocasional para presentar su renuncia

\footnotetext{
103 PASCUAL SASTRE, 2018: 294.

104 ROMANONES, 1965: 94.
} 
un asunto de Artillería. Pero en realidad, «aquel engañado príncipe se encontró prisionero de los radicales y no vio medio de romper sus ataduras sin desatar los vientos revolucionarios $\rangle^{105}$. Tras su abdicación, el 10 de febrero de 1873 , para sí y sus hijos, al día siguiente se proclamó la república. De este momento fue testigo el intelectual gallego Curros Enríquez, quien escribió al respecto: «Me retiraba de la tribuna pública del Congreso de los Diputados (...) donde acababa de proclamarse la República (...), sin costar a mi patria una sola gota de sangre (...), orgulloso de haber asistido a aquella proclamación (...) $\rangle^{106}$. Nada más proclamarse el nuevo régimen se constituyeron las Juntas revolucionarias en las principales ciudades de Galicia. Amadeo I había pasado a la historia.

\section{Bibliografía}

Amicis, Edmundo de, España. Impresiones de un viaje hecho durante el reinado de D. Amadeo I, Barcelona, Biblioteca Maucci, 2002 [1906]. [Traducción castellana de Cátulo Arroita].

Anderson, Benedict, Imagined Communities. Reflections on the Origin and Spread of Nationalism, London/New York, Verso, 1983. [Traducción al castellano en Madrid, Fondo de Cultura Económica Española, 2006].

Bagehot, Walter, The English Constitution, (edited by Paul Smith), Londres, University of Southampton, 2001 [1867]. [Traducción al castellano en Madrid, CEPC, 2010].

Bahamonde, Ángel, Historia de España: siglo XIX, Madrid, Cátedra, 1994.

Banerjee, Milinda, Backerra, Charlotte y Sarti, Cathleen (eds.), Transnational Histories of the «Royal Nation», Cham, Palgrave Macmillan, 2017.

Barral Martínez, Margarita, A visita de Isabel II a Galicia en 1858. Monarquía e provincialismo ao servizo da nacionalización, Santiago de Compostela, Sotelo Blanco, 2012.

Barral Martínez, Margarita, «Performing Monarchy and national identity in the liberal culture: the case of Galicia (1858)», Ler História, 68 (Lisboa, 2015): 69-84, http://lerhistoria.revues.org/1742, doi: 10.400/lerhistoria.1742

Barral Martínez, Margarita, «Visitas reales e identidad nacional en la segunda mitad del siglo XIX: el caso de Galicia (1858-1881)», en Pilar Folguera, Juan Carlos Pereira, et al., Pensar en la Historia desde el siglo XXI, Madrid, UAM Ediciones, 2015: 3919-3931.

Barral Martínez, Margarita (ed.), Alfonso XIII visita España. Monarquía y nación, Granada, Comares, 2016.

Barral Martínez, Margarita, «La identidad nacional-monárquica en Galicia durante el reinado de Alfonso XII», en Raquel Sánchez (ed.), Un rey para la nación. Monarquía y nacionalización en el siglo XIX, Madrid, Sílex, 2019 (en prensa): 105-130.

105 PI y MARGALL, 1970 [1873]: 110.

106 CURROS ENRÍQUEZ, 1906, tomo V: 208-209. 
Barreiro Fernández, Xosé Ramón, O carlismo galego, Bertamiráns, Laiovento, 2008. Billig, Michael, Banal Nationalism, Londres, Sage, 1995. [Traducida al castellano en Madrid, Capitán Swing, 2014].

Bolaños Mejías, Carmen, El reinado de Amadeo I y su monarquía constitucional, Madrid, UNED, 1999.

Brice, Catherine, Monarchie et identité nationale en Italie (1861-1900), París, EHESS, 2010.

Brice, Catherine y Moreno Luzón, Javier, (dirs.), «Monarchia, nazione, nacionalismo in Europa (1830-1914)», Memoria e Ricerca, 42 (Bologna, 2013).

Burdiel, Isabel, Emilia Pardo Bazán, Barcelona, Taurus, 2019.

Burdiel, Isabel, Isabel II. No se puede reinar inocentemente, Madrid, Espasa Calpe, 2004.

Cammarano, Fulvio, «Il 'garante interesato': monarchia e politica in Italia e Gran Bretagna dopo il 1848», en Giulia Guazzaloca, Monarchia e legitimazione in Europa tra Otto e Novecento, Soveria Mannelli, Rubbettino, 2009: 67-91.

Cannadine, David, «The Context, Performance and Meaning of Ritual: The British Monarchy and the "Invention of Tradition", c. 1820-1977», en Eric Hobsbawm y Terenger Ranger (dirs.), The Invention of Tradition, Cambridge, Cambridge University Press, 1983: 101-164. [Traducida al castellano en Madrid, Crítica, 2005].

Curros Enríquez, Manuel, «El Aniversario», en Remedios Ilustrado, Remedios, Cuba, 1906, tomo V: 208-209.

Fontana, Josep, La época del liberalismo. Historia de España, Barcelona, Crítica/ Marcial Pons, 2007, vol. 6.

Geertz, Clifford, «Centers, Kings, and Charisma: Reflections on the Symbolics of Power», en Sean Wilentz (ed.), Rites of Power: Symbolism, Ritual, and Politics since the Middle Ages, Philadelphia, University of Pennsylvania Press, 1999: 13-88.

González López, Emilio, Historia de Galicia, La Coruña, La Voz de Galicia, 1980.

Guazzaloca, Giulia (a cura di), Sovrani a metà. Monarquia e legittimazione politica tra Otto e Novecento, Soveria Mannelli, Rubbettino, 2009.

Gutiérrez Lloret, Rosa Ana y Mira Abad, Alicia, «Ser reinas en la España constitucional: legitimación y deslegitimación simbólica de la monarquía nacional», Historia y Política, 31 (Madrid, 2014): 139-166.

Higueras Castañeda, Eduardo, «Las elecciones serán todo lo puras que puedan serlo en España: la corrupción electoral durante el reinado de Amadeo de Saboya (18711872)», en Borja de Riquer, Joan Lluís Pérez, Gemma Rubí et al., La corrupción política en la España Contemporánea. Un enfoque interdisciplinar, Madrid, Marcial Pons, 2018: 531-544.

Kleinmann, Han-Otto, «Amadeo I (1870-1873)», en Walther L. Bernecker, Carlos Collado y Paul Hoser (eds.), Los Reyes de España. Dieciocho retratos históricos desde los Reyes Católicos hasta la actualidad, Madrid, Siglo XXI, 1999: 255-267.

La Parra, Emilio (coord.), La imagen del poder. Reyes y regentes en la España del siglo XIX, Madrid, Síntesis, 2011.

Levra, Umberto, «Vittorio Emanuele II», en Mario Isnenghi (ed.), I Luoghi della memoria. Personaggio e date dell'Italia unita, Roma/Bari, Editori Laterza, 1997: 47-64. 
Mancuso, Claudio, La patria in festa. Ritualità pubblica e religioni civile in Sicilia (1860-1911), Roma/Palermo, La Zisa, 2013.

Mira Abad, Alicia, «La imagen de la Monarquía o cómo hacerla presente entre sus súbditos: Amadeo y M ${ }^{\mathrm{a}}$ Victoria», Mélanges de la Casa de Velázquez, 37/2 (Madrid, 2007): 173-198.

Mira Abad, Alicia, «La monarquía imposible: Amadeo I y María Victoria», en Emilio La Parra, (coord.), La imagen del poder. Reyes y regentes en la España del siglo XIX, Madrid, Síntesis, 2011: 283-331.

Moreno Luzón, Javier, «Alfonso el Regenerador. Monarquía escénica e imaginario nacionalista español, en perspectiva comparada (1902-1913)», Hispania, LXXIII/244 (Madrid, 2013): 319-348.

Nardi, Federico, "“Ante la imagen de la Virgen de la Monarquía y sobre la tumba del restaurador de la misma”. I viaggi della famiglia reale al santuario de Covadonga in età contemporanea (1858-1918)», Spagna contemporanea, 54 (Alessandria, 2018): 33-61.

Olechnowicz, Andrzej, «Historians and the modern British monarchy», en Andrzej Olechnowicz (ed.), The Monarchy and the British Nation. 1780 to the Present, Cambridge, Cambridge University Press, 2007.

Pardo Bazán, Emilia, La Tribuna, Madrid, Cátedra, 2002 [1883].

Pascual Sastre, Isabel, La Italia del Risorgimento y la España del Sexenio democrático. De los precedentes de la crisis del Sexenio, 1860-1874, tesis doctoral, Universidad Complutense de Madrid, 1995.

Pascual Sastre, Isabel, «La Corte bajo una Constitución democrática. La Casa Real en el reinado de Amadeo I», en Raquel Sánchez y David San Narciso (coords.), La cuestión de palacio. Corte y cortesanos en la España contemporánea, Granada, Comares, 2018: 263-299.

Pérez Galdós, Benito, Episodios Nacionales. Quinta Serie: España sin rey y Amadeo I, (ed. Francisco Caudet), Madrid, Alianza, 2007 [1907-1910].

Pi y Margall, Francisco, El reinado de Amadeo de Saboya y la República de 1873, (prólogo de Antoni Jutglar), Madrid, Seminario y Ediciones, 1970 [1873].

Pirala, Antonio, El rey en Madrid y en provincias, Madrid, Impresor de Cámara, 1870.

Ramil, Ramón et al., Historia de Ferrol, A Coruña, Vía Láctea, 1998.

Reyero, Carlos, Monarquía y Romanticismo. El hechizo de la imagen regia, 18291873, Madrid, Siglo XXI, 2015.

Roca, José Pastor de la, Crónica del viaje a Alicante de SS.MM. Amadeo I y María de la Victoria en marzo de 1871, Alicante, Imprenta de la viuda de Juan J. Carratalá, 1871.

Romanones, Conde de [Álvaro de Figueroa y Torres], Amadeo de Saboya, "el rey efimero», Madrid, Espasa-Calpe, 1935.

Romanones, Conde de [Álvaro de Figueroa y Torres], Amadeo de Saboya, el rey efimero: España y los orígenes de la guerra franco-prusiana de 1870, Madrid, España-Calpe, 1965.

Rubí, Gemma, «La corona en la construcció de la nació. La visita del rei Alfons XIII a Catalunya l'abril de 1904», en Ramon Arnabat y Antoni Galvaldà (eds.), Prejetes nacionals, identitats i relacions Catalunya-Espanya, Catarroja, Afers, 2012: 289-306. 
Rubí, Gemma, «La corona y la nación. Las visitas reales como políticas públicas», en Pere Gabriel, Jordi Pomés y Francisco Fernández (eds.), España Res Publica. Nacionalización española e identidades en conflicto (siglos XIX y XX), Granada, Comares, 2013: 67-78.

Sagrera, Ana de, Amadeo y María Victoria, Palma de Mallorca, Impr. Mossèn Alcover, 1959.

Sapag Muñoz de la Peña, Pablo, «La Gaceta de Madrid como instrumento propagandístico de Amadeo de Saboya (1870-1873)», Historia y Comunicación Social, 11 (Madrid, 2006): 199-215.

Sellin, Volker, European Monarchies from 1814 to 1906: A Century of Restoration, Berlín, De Gruyter, 2017.

Shubert, Adrian, Espartero, el pacificador, Barcelona, Galaxia Gutenberg, 2018.

Sierra, María, «La vida política», en Jordi Canal (dir.), Historia contemporánea de España 2, 1808-1931, Barcelona, Fundación MAPFRE/Taurus, 2017: 297-345.

Speroni, Gigi, Amadeo de Saboya, rey de España, Barcelona, Editorial Juventud, 1989.

Thiesse, Anne-Marie, La création des identités nationales. Europe: siècles XIX-XX, París, Editions du Seuil, 1999. [Traducida al castellano en Ézaro ediciones, 2010].

Toledano González, Luís Ferrán, «El crucifijo y el baile. El trasvase de sacralidad entre el trono y la comunidad política en la familia real carlista, 1868-1876», Pasado y Memoria, 14 (Alicante, 2015): 79-107.

Van Osta, Jaan, «The Emperor's New Clothes: The Reappearance of the Performing Monarchy in Europe, c. 1870-1914», en Jeroen Deploige y Gita Deneckere (eds.), Mystifying the Monarch: Studies on Discourse, Power and History, Amsterdam, Amsterdam University Press, 2006: 181-192.

Viana, Víctor, «El desplante vilagarciano al rey Amadeo I de Saboya», Faro de Vigo, Vigo 28-12-2012: 1-3. http//:www.farodevigo.es/portada-arousa/2012-12-28

Vilavedra Fernández, Dolores, Historia da literatura galega, Vigo, Galaxia, 1999.

Viroli, Maurizio, Por amor a la Patria, Barcelona, Deusto/Planeta, 2019 [2005] [Tradución al castellano de Patrick Alfaya, For Love of Country, Oxford, Oxford University Press, 1995].

Williams, Richard, The Contentious Crows. Public Discussion of the British Monarchy in the reign of Queen Victoria, Hants, Ashgate, 1997.

Recibido: 14/01/2018

Aceptado: 06/05/2019

Hispania, 2019, vol. LXXIX, nº 262, mayo-agosto, págs. 389-414, ISSN: 0018-2141, e-ISSN: 1988-8368 